\title{
OPTICAL OCEANOGRAPHY: THE STATE OF THE SCIENCE
}

\author{
The issue most critical to understanding ocean \\ optics as a pure science is the issue of closure.
}

\author{
By Richard W. Spinrad \\ Program Manager for Ocean Optics, Code 1125AO. \\ Office of Naval Research, 800 N. Quincy St., Arlington, VA 22217.
}

Current

efforts in this

field are aimed

at increased

resolution and

application

of ocean

color, and

interpretation

and development

of pow'erful, low-

cost, portable

airborne remote

sensing systems.
A

group of merchant marines and a Jesuit priest started a scientific revolution aboard the vessel L'Immacolata Concezione during a six week voyage in 1865 . The priest, a scholar by the name of Angelo Secchi, with the able assistance of the crew of the ship, repeatedly lowered several weighted disks of different colors and sizes into the Mediterranean and made some fascinating revelations about the color and clarity of the sea water at different locations as a function of such variables as solar elevation and sea state (Secchi, 1866). The measurement of Secchi depth, as it has come to be known, (i.e. the depth, in meters, at which a calibrated white disk of specified diameter and reflectance is no longer visible when lowered and observed on the ship's sun side) is still, nearly 125 years later, one of the most common measurements of hydrologic optics. Nonetheless, the method of its deployment obviates the very subjective nature of the data. To this end scientists have endeavored to develop evermore accurate optical techniques to address the needs of the many disciplines that are oceanography. The science of optical oceanography has developed over the last half century as an interdisciplinary field characterized by rapid changes in techniques and adaptation of new technologies.

All four of the traditional oceanographic sciences have embraced optical oceanography as an independent source of measurements and variables. Examples of the applications of optics include tracking of particle layers to demonstrate the existence and magnitude of deep ocean currents, (e.g. Biscaye and Eittreim, 1977; Weatherly et al., 1980), the quantification of sediment transport (e.g. Spinrad and Zaneveld, 1982), the spatial signature of thermal vents (Baker et al., 1985), the science of bio-optics, originally defined by Smith and Baker (1978), by which the measurement of sunlight at depth and biological primary productivity may be accurately modeled and predicted, and marine photochemistry, involving the study of the energy transfer between radiance input and chemical species transformation in the photic zone. The examples given above are just a very small representation of the integral role ocean optics plays in the marine sciences today. In any overview of the field of ocean optics there are three issues that that should be addressed: a) the history/evolution of the field; b) the significance of the "technology transfer" aspect of marine optics and, most importantly; c) the issues critical to the enhancement of optical oceanography.

The field of optical oceanography is reasonably new and unknown. In the middle of the 20th century many oceanographers (themselves a new breed) began to experiment with traditional optical techniques in application to their new problems. Originally, the use of optics in the sea was restricted to either shipboard laboratory quantitative assessments of discrete samples drawn from the water column (e.g. absorption or fluorescence measurements such as those described by Yentsch and Ryther, 1959, and Yentsch and Menzel, 1963), or relatively lower resolution measurements made in situ with newly developed sensors (e.g. the photographic nephelometers of Bauer and Morel, 1967 or Thorndike and Ewing, 1967 which provided some of the first data revealing the nature of intermediate particle layers in the open ocean). The latter half of the 20th century has been a period of burgeoning development in the design of high resolution, in situ optical probes for marine research. Researchers in Denmark (including Jerlov, Kullenberg, and Hojerslev) took a strong lead in the development of light scatter meters. Simultaneously the bastion of optical oceanography in the U.S., the Visibility Lab at Scripps (whose notable researchers have included S.Q. Duntley, Rudy Preisendorfer, Ray Smith, Ros Austin, Jim Mueller, Karen Baker and numerous others) worked closely with the Navy in research, development, testing, evaluation, organization and analysis using of a wide variety and large number of integrated optical systems designed to measure the complete suite of parameters defining the spectral radiance field. During the 1970 's and 1980 's new technologies (e.g. lasers, photodiodes and the general miniaturization of electro- 
optical components) have allowed the optical oceanography community to develop highly sophisticated and accurate sensors (including beam transmissometers, fluorometers and spectral radiometers designed to measure total, as well as upwelling or downwelling radiances and irradiances) which are now adequately energy-efficient to be deployable on long term moorings. The effort in developing new instrumentation has exploded in the last ten years (as evidenced by the incorporation of at least two privately held firms solely dedicated to research, development and manufacturing in the field of hydrological optical instrumentation: Biospherical Instruments, Inc. and Sea Tech Inc.).

Additionally, the advent of satellite sensing techniques has given birth to the need for a strong remote sensing algorithm support base and ground truth capability within the ocean optics community. Current efforts in this field are aimed at increased resolution and application of ocean color interpretation, and the development of powerful, low-cost, portable airborne remote sensing systems.

$\mathrm{T}$ he laboratory is where the hydrologic optics community has, perhaps, been most creative in transferring technologies. Processes such as the absorption due to water and dissolved or suspended particles (including phytoplankton), or the variability of light scatter within and between phytoplankton species, or the expected behavior of a photon penetrating the sea may best be answered in the controlled laboratory environment. These three examples dramatically demonstrate how technologies have been adapted from other fields for use in ocean optics. Ongoing lab programs in light absorption are using methods such as high precision photothermal and photoacoustic measurements to determine the spectral absorption of sea water. Flow cytometry ("borrowed" from the biomedical community where it is used in blood monitoring and oncology) has provided a groundbreaking tool for single cell observations of such phenomena as intracellular chlorophyll-a packaging and environmental control on phytoplankton refractive indices. Theoreticians in ocean optics, working on various aspects of radiative transfer, now routinely use simulation techniques (e.g. Monte Carlo) and image processing methodologies translated and modified from applications traditionally used in particle physics and optical engineering.

As indicated above, the issues facing the ocean optics community today include those applying to fields for which optics is a valuable tool as well as those issues of immediate importance to simply understanding ocean optics as a science unto itself. The former issues have been touched upon, briefly, in the discussions above. The issue most critical to understanding ocean optics as a pure science is the issue of closure. Simply defined, closure is that characteristic of optical oceanography by which all of the linear and non-linear optical processes in the sea come to summation and energy is conserved. Specifically, the sources (e.g. sunlight, skylight, fluorescence, bioluminescence, Raman scatter, Brillouin scatter, etc.), the sinks (spectral absorption by particles, water and dissolved material) and the distributions (transmission, reflectance out of the sea and volume scatter) must all be measurable and mutually compatible on a photon-budget basis. Addressing closure is a formidable task. The first necessary step is agreement in methodologies and measurements. To this end, for example, parallel efforts in the measurement of spectral absorption are presently being undertaken with the goal of achieving high resolution and complete spectral coverage through some degree of redundancy. Similarly, renewed emphasis is being placed on previously neglected processes such as Raman scatter in an effort to adequately account for all sources and sinks of energy regardless of biases toward their insignificance established by historic paradigms. Generally the issue of closure has induced a need for a more holistic approach to optics. Complete measurements of absorption, total scatter and attenuation are yet to be tested for closure even at one wavelength. where there is no non-linear input (in a monochromatic system theory states that attenuation = absorption + scatter). This is not only a significant problem for the ocean opticians; lack of closure even in the monochromatic system implies that either the measurements of absorption, scatter and/or attenuation are in error (which would be important to all the biologists, chemists, physicists and geologists using those optical measurements) or, that the very basic theory of light attenuation is in error (doubtful).

In the field there is still a paucity of data to adequately define the optical variability of the sea. The various sources of variability (e.g. spring phytoplankton blooms, sediment transport, aeolian transport of terrestrial dust) are reasonably well defined but their dynamic behavior is inadequately documented. Several major projects have been and will be underway to look specifically at optical variability (e.g. BIOWATT and Marine Light Mixed Layer) and hopefully additional multidisciplinary programs (e.g. STRESS, BECOST, GOFS and WOCE) will also observe processes and manifestation of optical variability in the sea. In short, there is a need to enlarge the data base of marine optics.

$\mathrm{T}$ he final thrust in ocean optics is one incorporating the knowledge gained from the closure effort with the measurements made in the field to yield a new capability in optics: predictability. Predictability requires the enhancement of ongoing modeling efforts.

The goal is the development of robust models that do not suffer from being overly general. The predictability that is gained from such models of the future will be of immeasurable value to the whole research community.

[ PLEASE TURN TO PAGE 35 ]
Complete

measurements

of absorption,

total scatter and

attenuation are

yet to be tested

for closure

even at one

wavelength,

where there

is no non-linear

input. 


\section{A Post-Graduate VieW [ CONTINUEd From Page 13 ]}

Thirdly, graduate schools need to recognize that entering students come from a variety of backgrounds, each with its own inherent strengths and weaknesses. Some allowance must be made for this in the graduate curricula.

One step that has been taken in this direction by the Joint Program is the introduction of a math course in the first summer. designed to help ensure that students do not start their first semester with a disadvantage in this area. Finally, departments offering bachelor's degrees in oceanography should track their graduates and see how they have fared in their further education and careers. This information, along with statistics from graduate departments of oceanography on the rate of acceptance of applicants and the fate of the admittees, classified by undergraduate major, should be useful in future evaluation of under- graduate programs.

\section{REFERENCES}

Maynard, S.D. 1986. Undergraduate marine science degrees: pros and cons Proceedings of the Pacific Congress on Marine Technology, PACON 86. Honolulu, MRM7: 38-46.

TABLE 1. A PARTIAL LIST OF INSTITUTIONS OFFERING BACHELOR'S DEGREES IN OCEANOGRAPHY OR MARINE SCIENCE. Florida Institute of Technology, FL

Humboldt State College. CA

Millersville State College, PA

Southampton College, NY

Stockton State College, NJ

Texas A\&M University at Galveston, TX

U.S. Naval Academy, MD

University of Miami, FL

University of Michigan, MI

University of South Carolina, SC

University of Washington, WA

\section{Satellite OCEan Color [ Continued From Page 20 ]}

Gordon, H.R., J.W. Brown and R.H. Evans. 1988. Exact Rayleigh scattering calculations for use with the Nimbus-7 Coastal Zone Color Scanner. Applied Optics 27:862-871.

Holligan, P.M. V. Viollier, D.S. Harbour, P. Camus, and M.ChampagnePhillippe. 1983. Satellite and ship studies of coccolithophore production along a continental shelf edge. Nature 304:339-342.

Joint EOSAT/NASA SeaWiFS Working Group. 1987. System concept for wide-field-of-view observations of ocean phenomena from space. EOSAT. 4300 Forbes Blvd. Lanham. MD 20706.

McClain. C.R. L.J. Pietrafesa and J.A. Yoder. 1984. Observations of Gulf Stream-induced and wind-driven upwelling in the Georgia Bight using ocean color and infrared imagery. J. Geophys. Res. 89:3705-3723.

Perry, M.J. 1986. Assessing marine primary production from space. Biosci.
36:461-467

Rampino, M.R. and T. Volk. 1988. Mass extinctions, atmospheric sulphur and climatic warming at the K/T boundary. Nature 33i:63-65.

Smith. R.C.. O.B. Brown, F.E. Hoge, K.S. Baker. R.H. Evans, R.N. Smith and W.E. Esaias, 1987. Multiplatform sampling (ship, aircraft, and satellite) of a Gulf Stream warm core ring. Applied Optic's 26:2068-2081.

U.S. Global Ocean Science Program Working Group. 1987. The U.S. Global Ocean Science Program, A strategy for understanding the role of the ocean in global change.

Yoder, J.A.. C.R. McClain, J.O. Blanton and L.-Y. Oey. 1987. Spatial scales in CZCS-chlorophyll imagery of the Southeastern U.S. continental shelf. Limn. Oceanogr.32:929-941.

\section{OPTICAL OCEANOGRAPHY [ CONTINUED FROM PAGE 23 ]}

\section{ACKNOWLEDGMENTS}

There are some $80-100$ researchers active in ocean optics in the Western world. Regrettably, space did not allow fair representation of all their efforts, past and present. The author is indebted to the community as a whole. Several individuals are owed special thanks for their comments and advice: Ros Austin. Ken Carder. Howard Gordon, Frank Hoge, Curt Mobley, Hasong Pak, Ray Smith, Charlie Yentsch and Ron Zaneveld.

\section{REFERENCES}

Baker, E.T., J.W. Lavelle, and G.J. Massoth. 1985: Hydrothermal particle plumes over the southern Juan de Fuca Ridge. Nature, 316:342-344.

Bauer, D. and A. Morel, 1967: Etude aux petits angles de l'indicatrice de diffusion de la lumiere par les eaux de mer. Ann. Geophys.. 23:109-123. Biscaye. P.E. and S.L. Eittreim, 1977: Suspended particulate loads and transports in the nepheloid layer of the abyssal Atlantic Ocean. Mar. Geol., $23: 155-172$

Secchi, A.. 1866: Relazione della esperienze fatta a bordo della Pontificia Pirocorvetta L'Imacolata Concezione per determinare la transparenza del mare /Reports on experiments made on board the Papal steam sloop L Imacolata Concezione to determine the transparency of the sea] in Sul moto ondoso del

mare e su correnti di erso specialmente su quelle littorali, by Comm. Dept. of the Navy Office of the Chief of Naval Operations. O.N.I. Trans. No. A-655. Op-923 M4B, 21 Dec., 1955.

Smith. R.C. and K.S. Baker. 1978: The bio-optical state of ocean waters and remote sensing. Limnol Oceanogr. 23:247-259.

Spinrad, R.W. and J.R.V. Zaneveld. 1982: An analysis of the optical features of the near-bottom and bottom nepheloid layers in the area of the Scotian Rise. J. Geophys. Res., 87:9553-9561.

Thorndike,E.M. and M. Ewing, 1967: Photographic nephelometers for the deep sea in Deep-Sea Photography, v. 3 Johns Hopkins University Press, pp. $113-116$.

Weatherly, G.L., E.A. Kelley, J.R.V. Zaneveld, H.Pak, M.J. Richardson. 1980: A deep narrow, thin filament of the western boundary undercurrent. EosTrans. AGU, $61: 1016$.
The

Yentch, C.S. and D.W. Menzel, 1963: Absorption curves of acetone extracts of deep water particulate matter. Deep-Sea Res.. 10:443-448.

Yentsch, C.S. and J.H. Ryther, 1959: A method for the determination of phytoplankton chlorophyll and phaeophytin by fluorescence. Deep-Sea Res. $6: 72-74$.

\section{OCEANOGRAPHY SOCIETY [ CONTINUED FROM PAGE 21]}

strength to a society in their own specialty. A new society would provide a mechanism for evaluating this strength, for focusing it , and maximizing its application. The changes which can be brought about in the world of social organizations by the activities of The Oceanography Society could well be comparable to the changes which were brought on-campus by the establishment of oceanography departments.

As in the universities, where all departments cooperating in the marine sciences saw those programs strengthened by the existence of an oceanography department in their midst, it is likely that the ocean-oriented programs of brother societies would be strengthened by their association with The Oceanography Society. A broader and deeper basis for support of all applications of ocean science, engineering, and technology could be tapped.
The potential of oceanography seems unlimited. The oceans constitute a major part of our planet. Understanding and fully utilizing the oceans will require all the knowledge of the basic sciences and all of the skills of engineering and technology. To obtain appropriate support and to seek this understanding effectively requires the coordination and focusing of the many different participating institutions and societies. A missing element has been a dedicated Oceanography Society.

\section{REFERENCES}

Knudsen, Vern O., Redfield, A. C.. Revelle. R., and Shrock. R. R., Education and Training for Oceanographers, Science, 111 (2895), p. 700-703. June 23. 1950.

Leipper. Dale F. The establishment of the Department of Oceanography in the Agricultural and Mechanical College of Texas [Now Texas A\&M University)] Trans. Am. Geophys. Un. 3I ( 5), October 1950.

Leipper, Dale F., Oceanography - A definition for Academic Use, Trans. Am. Geophys. Un. 42 (4), December 1961. 